\title{
Desaparición forzada y trauma cultural en México: el movimiento de Ayotzinapa
}

\author{
Enforced disappearance and cultural trauma in Mexico: \\ the Ayotzinapa movement
}

\author{
Tommaso Gravante / t.gravante@gmail.com \\ https://orcid.org/0000-0003-1168-931X \\ Universidad Nacional Autónoma de México, México
}

\begin{abstract}
The disappearance of 43 students from Ayotzinapa in 2014 breathed life into a broad social movement. What occurred this time to generate a broad mobilization of citizens? To answer this question, I believe we need to understand why and how Mexican society has framed the Ayotzinapa events. My starting hypothesis is that the Ayotzinapa events have produced a social process of collective trauma, and I will support this with Jeffrey Alexander's proposal of cultural trauma, rarely used when analyzing collective action. The analysis is based on ethnographic work carried out over one year (September 2014-2015) during the different demonstrations to show solidarity with the parents of the disappeared students, which were held in Mexico City, and 70 interviews held at the national demonstration on $26^{\text {th }}$ September 2015 to commemorate a year since the 43 rural teachers' college students went missing.
\end{abstract}

Keywords: victim movements, cultural trauma, enforced disappearance, emotions, violence.

Resumen: La desaparición de los 43 estudiantes de Ayotzinapa en 2014 dio vida a una amplia e inusual respuesta por parte de la sociedad civil mexicana. La pregunta que responde la investigación es: ¿qué sucedió en esta ocasión para generar una amplia movilización ciudadana? Con base en la propuesta de Jeffrey Alexander de trauma cultural, raramente utilizada en el análisis de la acción colectiva, analizaré el porqué y de qué forma la sociedad mexicana ha enmarcado los hechos de Ayotzinapa. El análisis se fundamenta en el trabajo etnográfico efectuado a lo largo de un año (septiembre 2014-2015) durante las distintas manifestaciones en solidaridad con los padres de los estudiantes desaparecidos emprendidas en la Ciudad de México y de 70 entrevistas realizadas en la manifestación nacional del 26 de septiembre de 2015, que conmemoraba un año de la desaparición de los 43 estudiantes normalistas.

Palabras clave: movimientos de víctimas, trauma cultural, desaparición forzada, emociones, violencia. 


\section{Introducción y planteamiento del problema ${ }^{1}$}

En América Latina, la desaparición forzada ha sido una estrategia empleada por las distintas dictaduras militares para infundir terror en los ciudadanos y eliminar a los sujetos que se consideraban peligrosos. En México, aunque nunca se vivió la experiencia de un golpe de Estado militar -desde la represión estudiantil de 1968 y la llamada guerra sucia en contra de las guerrillas-, las violaciones graves como la desaparición forzada, tortura y otros tratos crueles, inhumanos o degradantes se han trasformado en un modus operandi que no se ha limitado a la actuación aislada de funcionarios, sino a un fenómeno de carácter generalizado y operado por los cuerpos de las instituciones de seguridad, grupos paramilitares y organizaciones criminales (Open Society Foundations, 2016; Instituto Belisario Domínguez, 2016; CNDH, 2016; GTDFI, 2015). Los informes de la Secretaría de Gobernación mexicana y otros organismos independientes internacionales registran más de $20 \mathrm{mil} \mathrm{ca-}$ sos de desapariciones en el país (Segob, 2016; Open Society Foundations, 2016; CIDH, 2015).

A pesar de que la desaparición forzada en México registra niveles similares a aquellos países que han experimentado guerra civil y violencia política como Siria y Paquistán (GTDFI, 2015), en la última década la respuesta de la sociedad civil mexicana ha sido débil y discontinua, a diferencia de otros países como, por ejemplo, Guatemala, Argentina y Chile. La reciente Encuesta Nacional de Violencia Organizada (ENVO) ${ }^{2}$ (Schedler, 2014) destaca esta tendencia al mostrar que: el $89.4 \%$ de los entrevistados en 2013 se ha abstenido de participar en cualquier forma colectiva de protesta y el $75 \%$ ha declarado no tener conocimiento de la existencia de los movimientos de las víctimas de desaparición.

El 26 de septiembre de 2014, la muerte de seis personas y la desaparición forzada de 43 estudiantes de la normal rural de Ayotzinapa, en el estado de Guerrero, hizo emerger en México un amplio movimiento en solidaridad con los familiares de las víctimas, cuya principal consigna es la presentación con vida de estos jóvenes.

1 Esta investigación fue ganadora de la Seventh Worldwide Competition for Junior Sociologists seleccionada por la Gran Juria de la Asociación Internacional de Sociología.

2 La investigación ENVO que reconstruye las percepciones y actitudes de los ciudadanos y las élites fue de alcance nacional. Las encuestas en la población se realizaron entre octubre y noviembre de 2013 en vivienda, con una muestra de 2,400 casos; y entre noviembre de 2013 y febrero de 2014 de manera telefónica para las élites con una muestra de 629 casos. 
La respuesta que dio la sociedad mexicana a la desaparición de los estudiantes rompió esa tendencia hacia la inacción, dando lugar a un movimiento inédito para el país (Alonso-Sánchez y Alonso-Reynoso, 2015). Dicho movimiento se caracteriza por una alta participación de ciudadanos que no se vinculan a ningún sector permanentemente organizado de los movimientos sociales u organizaciones formales. Los datos del Laboratorio de Análisis de Organizaciones y Movimientos Sociales (LAOMS, 2015a y 2015b) del CEIICH-UNAM, que se vale de la metodología del Análisis de Eventos de Protesta, destacan que después de los acontecimientos de septiembre de 2014 hubo un incremento de los eventos de protesta, habiéndose realizado después de esta fecha el $47 \%$ de las acciones colectivas de todo 2014, año que tuvo un incremento de la protesta del $120 \%$ sobre la tendencia media anual.

Esto nos lleva a preguntar: ¿qué pasó en esta ocasión para generar una amplia movilización a lo largo de todo el país? La relevancia de la pregunta reside en el hecho de comprender por qué la sociedad civil mexicana no quiso ver la desaparición de los 43 estudiantes como un caso aislado más.

Para contestar esta interrogante, considero necesario, en primer lugar, comprender cómo la sociedad mexicana ha enmarcado la desaparición forzada de estos jóvenes. Mi hipótesis inicial es que los hechos de Ayotzinapa originaron un proceso social de trauma colectivo; por lo tanto, me apoyaré en la propuesta de Alexander (2002, 2004 y 2016), raramente utilizada en el análisis de la acción colectiva.

El texto se desarrollará de la siguiente forma: primero analizaré cómo determinadas emociones permiten enmarcar la desaparición forzada de los estudiantes como un trauma cultural colectivo. Segundo, apoyándome en la literatura sobre emociones y protesta, examinaré el proceso de politización del trauma colectivo que lleva a modificar la relación entre ciudadanos e instituciones públicas. Por último, a manera de conclusión, destacaré cómo la espiral de significados que desata el trauma cultural colectivo por los hechos de Ayotzinapa da lugar a una nueva narrativa social.

El análisis se fundamenta en un diseño de investigación constituido por dos etapas: 1) el trabajo etnográfico efectuado a lo largo de un año (septiembre 2014-2015) de manifestaciones realizadas en la Ciudad de México, lo cual nos permite comprender el papel de los participantes individuales, organizaciones y grupos, cómo se estructuraban los diversos actores y qué patrones de significado se repetían (Andretta y Della Porta, 2008; Andretta, et al., 2002; van Stekelenburg et al., 2012) y 2) las 70 entrevistas realizadas a lo largo de la manifestación nacional del 26 de septiembre de 2015, que conmemoraba un año de la desaparición de los 43 estudiantes normalistas. Se 
entrevistaron a 46 mujeres y 24 hombres, de los cuales el 16\% tenía 20 años o menos; el 28\%, entre 21-30 años; el 23\%, entre 31-40 años; el 15\%, entre 4150 años; el 10\%, entre 51-60; y el 8\%, 61 años o más. De los 70 entrevistados, 64 declararon no pertenecer a ninguna organización o contingente presente en la marcha. En el análisis se incorporan indistintamente las 70 entrevistas.

\section{Desde la plaza en Tlatelolco hasta la crueldad de Ayotzinapa: un largo ciclo de protesta}

En México, el 2 de octubre es una fecha de movilización social en la que se realiza una marcha conmemorativa por la masacre de estudiantes en la Plaza de las Tres Culturas, en Tlatelolco, ocurrida el mismo día de 1968. Como todos los años, miles de jóvenes, asociaciones en defensa de los derechos humanos, colectivos sociales y otras organizaciones de la sociedad civil se preparan para participar en dicha marcha, en la Ciudad de México.

El 26 de septiembre de 2014, un grupo de estudiantes de la Escuela Normal Rural Raúl Isidro Burgos de Ayotzinapa, en el estado de Guerrero, tomaron de manera pacífica algunos autobuses del servicio de transporte público del municipio de Iguala -en el mismo estado-, con la intención de trasladarse a la Ciudad de México y participar en la movilización social del 2 de octubre. En la misma noche, los autobuses fueron interceptados por la policía municipal de Iguala y atacados con armas de fuego. Como resultado, 7 personas murieron, uno de ellos fue desollado y le arrancaron los ojos, y 43 jóvenes entre los 18 y 23 años, hijos de campesinos pobres de la región, que estudiaban para ser maestros de primaria en alguna de las escuelas públicas rurales, fueron detenidos por policías y desaparecidos. ${ }^{3}$

Como hemos anticipado, la inseguridad y la violencia en México no iniciaron con la barbarie de Ayotzinapa. Antes y después de Ayotzinapa han ocurrido en el país graves violaciones a los derechos humanos. Empezando por la masacre de Tlatelolco, cometida diez días antes de la inauguración de los Juegos Olímpicos de la Ciudad de México en 1968. También, la desaparición de personas en México es frecuente. Según el Registro Nacional de Personas desaparecidas o extraviadas de la Secretaría de Gobernación (Segob, 2016), en el periodo de 2006 a 2014 se denunció la desaparición de 22,610 personas.

Sin embargo, la desaparición forzada de los 43 estudiantes normalistas en septiembre de 2014 provocó la ola de protestas más importante, por su 3 Para más detalles sobre los hechos de Ayotzinapa se puede consultar la amplia bibliografía comentada de Krotz y Llanes (2015). 
número y extensión, que ha registrado la historia reciente del país. En varias ciudades del extranjero también se presentaron protestas por el mismo caso. $\mathrm{Y}$ en la búsqueda de dichos normalistas se descubrieron decenas de fosas clandestinas en Guerrero y en otros estados de México.

Entonces, si la desaparición forzada de personas y las violaciones a los derechos humanos son tan frecuentes y regularmente pasan desapercibidas o son olvidadas rápidamente, ¿ por qué la brutalidad policiaca y las desapariciones forzadas de los 43 estudiantes despertaron protestas a una escala nunca antes vista? Estas son las preguntas principales que inspiraron esta investigación, cuyos resultados presentaré en las páginas que siguen.

\section{La desaparición forzada como un trauma cultural colectivo}

\section{La representación social del estado traumático}

Como destaca Alexander (2002, 2004, 2016), el trauma cultural no es algo que existe naturalmente, sino un proceso sociocultural construido por la sociedad. En este trabajo, así como en la propuesta de Alexander (2004), el evento traumático es utilizado como marco interpretativo; es decir, son los mismos protagonistas quienes se describen como traumatizados. Esto sucede cuando el entorno individual y/o colectivo cambia repentinamente de manera inesperada y desagradable (Alexander, 2004: 2). Sin embargo, la construcción del significado del trauma no es el resultado del evento en sí - como la desaparición de los 43 estudiantes-, sino el resultado de un proceso más complejo: mientras la experiencia del dolor y del duelo es un hecho personal, compartir el trauma depende de la interpretación cultural que subyace a los procesos colectivos (Alexander, 2016: 14).

Como destaca Alexander, un mismo evento traumático, como es el genocidio de masas, puede ser interpretado de formas distintas con base en el contexto social e histórico, y solamente en algunas ocasiones da lugar al proceso social del trauma cultural (Alexander, 2004 y 2016). Por ejemplo, años antes del Holocausto del pueblo judío, durante la invasión a China, en 1938, el ejército japonés masacró a más de 300 mil civiles en Nanking. El trauma por este hecho nunca se extendió más allá del territorio chino, lo cual permitió que en Japón no se desarrollara un proceso social de trauma cultural respecto a las víctimas de Nanking.

De forma diferente, la exposición pública del Holocausto hizo posible, por ejemplo, que el pueblo alemán desarrollara, después de tres generaciones, un trauma cultural basado en el sentimiento culpa y de responsabilidad, pese 
a que muchos ciudadanos alemanes no tenían vinculación con el régimen nazi (Giesen, 2004). Por lo tanto, el proceso del trauma cultural y la construcción del significado del trauma son procesos dinámicos que varían en función de la cultura y el contexto socio-histórico.

Además, la construcción del significado alrededor del trauma se vincula también a la dimensión emocional de las personas, en particular a emociones como la amenaza, el miedo y la inseguridad. La forma en que los sujetos interpretan sus emociones alrededor del evento traumático construye lo que Alexander (2004: 10) llama el estado traumático -traumatic status-. En el caso de Ayotzinapa, el estado traumático que emerge desde la desaparición de los estudiantes es determinado por la sensación de los ciudadanos de sentirse directamente amenazados, no solamente ellos sino también sus seres queridos, como lo muestran estos extractos: "Porque esta vez desgraciadamente fueron ellos, ¿pero mañana quién será?” (I.45). y "El día de mañana le puede pasar al mío [su hijo]" (I. 43).

Por lo tanto, también en el caso de las desapariciones forzadas de Ayotzinapa, así como destaca Alexander (2004), lo que caracteriza la creación del estado traumático no es el acontecimiento en sí, sino su propia interpretación por parte de los sujetos, ya que el estado traumático puede ser atribuido a un fenómeno real o imaginario. A diferencia del enfoque psicoanalítico de Caruth (1996), el cual subraya la dimensión inconsciente de las emociones en el trauma, considero que es la capacidad de las personas de crear, manejar y transformar sus emociones (Hochschild, 1975 y 1979) la que determina la construcción simbólica del evento traumático.

En Ayotzinapa, el estado traumático es el resultado del significado simbólico y cultural que viene atribuido al shock y al miedo generados por la desaparición de los estudiantes, como lo comprueba este testimonio: "Lo que ha pasado a los estudiantes puede pasar a los hijos de cualquiera, aunque yo entiendo que aquí en la Ciudad de México es un poco más difícil” (I27). Además de emociones como el miedo y la amenaza que vinculan directamente las personas al evento traumático -la desaparición forzada-, hay otras emociones que entran en la construcción del trauma colectivo y relacionan a las víctimas con los otros.

El trauma que emerge a nivel colectivo es el producto también de la empatía y de la solidaridad de las personas externas al evento (los otros) con los estudiantes desaparecidos y los padres de las víctimas, y de la profunda disconformidad de la colectividad que siente que su identidad está en peligro (Alexander, 2004). Como en el caso del Holocausto (Alexander, 2016), el trauma es el resultado de la reelaboración del dolor compartido colectivamente 
por los sujetos (tanto las víctimas como los externos), que se convierte en una amenaza al "sentido que ellos dan de sí mismos, desde donde vienen y dónde quieren ir" (Alexander, 2004: 10). Para concluir, el evento traumático, como es la desaparición forzada, se interpreta de tal forma que deja marcas indelebles en la comunidad afectada, rediseñando sus memorias y cambiando su identidad futura de una vía irrevocable (Alexander, 2004).

Las emociones que vinculan a los otros con las víctimas son fundamentales en el proceso de construcción del trauma cultural. La ausencia de empatía, por ejemplo, puede llevar a lo que Alexander (2004) llama el rechazo de la existencia del trauma, como se puede observar actualmente en una parte de la sociedad japonesa que todavía rechaza o minimiza la masacre de Nanking en China.

\section{La humanización de las víctimas y el círculo del nosotros}

La interpretación que dan las personas de las emociones que emergen del evento traumático transforma también la imagen de las víctimas. Como analiza Alexander (2016) en sus estudios sobre el Holocausto del pueblo judío, un elemento constitutivo del estado traumático es el proceso de humanización de las víctimas. En lugar de ver a las víctimas judías de los nazis como una masa despersonalizada y caótica, la cultura popular occidental empezó a personalizarlas y diferenciarlas. Identificarlas claramente como seres humanos permitió a los occidentales no-judíos, por primera vez, experimentar una intensa identificación emocional con los seis millones de judíos víctimas del nazismo (Alexander, 2016: 5-6).

En el caso de los desaparecidos de Ayotzinapa, la resignificación de las víctimas de la desaparición como seres humanos posibilita a los demás vivir una identificación emocional con las víctimas, como destacan estos testimonios: "Nosotros somos estudiantes, ¿y qué habría pasado si hubiéramos sido nosotros?" (I.66), "Pienso en cómo sufren los padres" (I.14) o "El dolor de los padres, como madre lo siento y es muy difícil” (I.53).

Además, en el caso investigado, se puede observar un punto de ruptura donde las víctimas dejan de ser cifras anónimas para convertirse en seres humanos, lo cual transforma la desaparición de los estudiantes en una crisis social: las imágenes del cuerpo con el rostro desollado de uno de los jóvenes asesinados la noche del 26 de septiembre de 2014. Ver aquellas imágenes y asociar esa muerte a la biografía de un estudiante, padre de una bebé, rompió con el anonimato que caracteriza a las numerosas víctimas de desaparición en México. 
Ese proceso llevó a la gente a reflexionar sobre lo que sucedió y a actuar en consecuencia, como lo declara un entrevistado: "No era este mundo, era otro, entonces cuando esto pasa, cuando yo veo la foto que empieza a circular en redes pensé que hablaban de otro México. [...] Esto fue lo que más me dolió y me hizo llorar" (I.64). Para combatir la deshumanización de la violencia ejercida sobre los estudiantes -que se refleja en las palabras de este entrevistado: "Los cazaron como animales, persiguieron como animales a los 43 estudiantes" (I. 58)-, emerge la necesidad de humanizar y personalizar a las víctimas. Eso posibilita que los estudiantes desaparecidos se transformen en 43 rostros y nombres con 43 historias personales. Este proceso de humanización crea un sentido de identificación y lleva a la ciudadanía "a no olvidarlos y exigir justicia" (I.16).

El proceso de humanización de las víctimas, además de contribuir a la emergencia del estado traumático, permite ampliar lo que Alexander (2004) llama el círculo del nosotros -circle of the we-. Reconocer a la víctima como un ser humano, identificarse con los estudiantes desaparecidos o con sus padres, expande, fortalece y sustenta el sentido de identidad colectiva de una comunidad.

La ampliación del círculo del nosotros permite que una parte de la sociedad civil mexicana, como primer resultado, supere las diferencias entre manifestantes, la mayoría de clase media y que viven en la capital, y los normalistas y sus familiares, originarios de un entorno rural e indígena, que sigue siendo estigmatizado en la cultura mexicana. Este resultado coincide con otros casos de estudio, como el del Movimiento de las Mujeres de Negro en Israel y Palestina, que al humanizar a las víctimas de los otros y compartir el mismo dolor y duelo lograron superar las diferencias nacionales (Benski, 2005 y 2011).

El círculo del nosotros, que se amplia gracias al proceso de humanización de las víctimas, se fortalece también con la percepción de vivir en una sociedad bajo amenaza, o de una comunidad bajo ataque, como pasó con la comunidad judía después del Holocausto (Alexander, 2002 y 2016) o en la comunidad LGBT en Estados Unidos, durante la crisis del Sida en los años noventa (Gould, 2009).

La ansiedad y el miedo de que "esto está sucediendo en todos lados. Son nuestros hijos y el día de mañana le puede pasar al mío” (I.43), posibilitan reelaborar los hechos de Ayotzinapa construyendo un "nosotros"; es decir, una identidad colectiva que se basa en la amenaza, como lo destaca este entrevistado: "Ya vivimos aquí con miedo, porque si no es el gobierno son los policías; desgraciadamente muchas veces los policías son corruptos. Ya la gente vive con miedo. Aquí decimos 'somos libres, ¿pero hasta cuando?’” (I.8). 
La humanización de las víctimas y la ampliación del círculo del nosotros ocasiona que la comunidad identifique la causa moral del trauma. Los miembros de la comunidad que se sienten bajo amenaza definen sus relaciones de solidaridad, para compartir el sufrimiento de los otros y abrir la posibilidad de que el mismo trauma no se repita. De esta forma, el evento que genera el trauma experimenta un proceso de de-construcción política y simbólica (Alexander, 2016: 8).

En este proceso, el evento que genera el trauma es universalizado y se convierte en el símbolo de la violencia contra los miembros de cualquier colectividad estigmatizada, como pasó con el Holocausto (Alexander, 2016). En México, la desaparición forzada de los estudiantes, es decir, "todo lo que los 43 estudiantes representan" (I. 31), se transformó en un marco de significación política, constituido por diferentes emociones morales que emergieron en las entrevistas, como: dignidad, resistencia, esperanza; pero al mismo tiempo, por las de: impunidad, impotencia, injusticia e inseguridad. Proceso que analizamos en el apartado siguiente.

\section{El proceso de politización del trauma cultural}

La construcción del trauma cultural alrededor de un evento traumático como la desaparición forzada desencadena lo que Alexander (2004: 11) llama una espiral de significados, que involucra un cambio colectivo en la conciencia, las memorias y la identidad. Este cambio se manifiesta con el desarrollo de relaciones entre eventos previos aparentemente no relacionados con el evento traumático, estructuras sociales, percepciones individuales y acciones colectivas (Alexander, 2004: 1).

En el caso mexicano, enmarcar la desaparición forzada de los estudiantes como un trauma cultural hace emerger una relación de significados entre los hechos de Ayotzinapa y otros eventos aparentemente desvinculados, porque acontecieron en otro contexto histórico de la sociedad mexicana; por ejemplo, las protestas de 1968, como lo menciona este testimonio de un joven de treinta años que no vivió esos hechos: "A mí me recordó mucho lo del '68, una desgracia muy grande para el pueblo de México” (I.45). En la práctica, emerge una continuidad simbólica entre hechos pasados y el evento de Ayotzinapa, fortaleciendo el valor simbólico del evento traumático; he aquí las palabras de un entrevistado: "No son sólo 43, son miles de desaparecidos de forma violenta" (I58).

Otra relación que emerge desde esta espiral de significados, como sugiere Alexander (2004), es aquella entre el evento traumático y los elementos 
estructurales aparentemente externos al evento; por ejemplo, la presencia del ejército en las calles o la crisis económica que está viviendo el país, los cuales se suman al descontento que causó la movilización: "Estamos aquí por todo el desempleo" (I.5). A eso se suma la relación entre el evento traumático y las percepciones individuales, como es la percepción de vivir en un lugar no seguro: "México se ha convertido en un país de suma delincuencia" (I.45), o la idea de impunidad: "Porque hay muchísima impunidad en México" (I.1). Por último, destaca la relación entre el evento traumático y la acción colectiva, como es la participación en las manifestaciones y la idea de "seguir luchando por todos los otros casos" (I.35).

Como hemos mostrado, la espiral de significados que se desarrolla a partir del trauma cultural hace que la desaparición de los estudiantes de Ayotzinapa no sea un hecho aislado más, sino el resultado de una serie de circunstancias externas al trauma, percibidas por las personas como injustas. Esta espiral de significados hace que el proceso que lleva a la movilización social se nutra no solamente del deseo de que el trauma de la desaparición forzada no se repita, sino también de que se obtenga justicia para los otros casos y, por lo general, se ponga fin al clima de inseguridad y amenaza percibido.

Los elementos antes mencionados contribuyen a lo que sugerimos llamar un proceso de politización del trauma cultural; es decir, la dimensión simbólica del trauma cultural y las emociones vinculadas a este permiten construir un discurso político alrededor del trauma y enmarcar políticamente la experiencia de violencia vivida, como sucedió con el Holocausto (Alexander, 2016), o en otro caso distinto, con las víctimas de incesto en Estados Unidos (Champagne, 1996).

Esto es posible no sólo gracias a la espiral de significados que permite el desarrollo de una serie de relaciones inesperadas, sino a que el proceso de politización del trauma se determina en función de dos tipologías de emociones: las vinculadas al trauma -emotions of trauma-, como dolor, miedo, vergüenza e impotencia; y las que emergen desde la experiencia de resistencia al trauma -emotions of resistence-, como orgullo, felicidad, confianza, seguridad o la justa rabia (Whittier, 2001).

Por un lado, son estas últimas las que construyen un discurso politizado del trauma de la violencia sufrida, enfocándose en la importancia de la recuperación y de la resistencia individual y colectiva (Champagne, 1996). Por otro, las emociones de resistencia posibilitan sobrellevar las primeras y generar energía emocional (Collins, 2001 y 2012; Jasper, 2011). Esa energía, que emerge en los momentos colectivos y en los rituales, coadyuva al cambio social animando a los sujetos, como un carburante para la acción colectiva, 
ya que "cada victoria, aunque pequeña, produce confianza, atención y energía emocional, elementos que serán una ventaja en futuras acciones” (Jasper, 2011:296).

De esta forma, la manifestación de septiembre de 2015 se convierte también en un dispositivo emocional capaz de alimentar, sobre todo, la esperanza en cuanto "estamos dando un paso más. Somos más los del pueblo que el gobierno. Si nos unimos, ¡sí se puede!” (I. 47); y la alegría, "porque aunque no nos oigan, somos muchos de varios estados y países, y si todos nos juntamos podemos hacer justicia" (I. 51); emociones que resultan fundamentales para evitar el agotamiento de un movimiento (Poma y Gravante, 2016).

La manifestación pública de las emociones de resistencia es importante en tanto permite mostrar que las víctimas pueden recuperarse, por ejemplo, de la violencia o del duelo, y empuja a movilizarse a quienes tienen miedo de vivir la misma experiencia -como en el caso de los entrevistados-: "El hecho de que hay muchos desaparecidos en México genera una situación insoportable, entonces estoy aquí para manifestar que no queremos más desaparecidos, queremos educación" (I.31).

En los movimientos de víctimas analizados por Champagne (1996) y Whittier (2001), las emociones de resistencia emergieron desde un repertorio emocional (Jasper, 1998), perteneciente al movimiento de mujeres de la década de 1960 en Estados Unidos; es decir, de experiencias políticas que públicamente reivindicaron el derecho a expresar lo que Whittier (2001) define como las emociones de oposición -oppositional emotions-, como el dolor, el miedo, la rabia y la resistencia.

En México, durante la marcha de Ayotzinapa, el proceso de politización del trauma se construye gracias a un repertorio emocional de otras experiencias de protestas -como los movimientos de familiares de desaparecidos de la guerra sucia en la década de 1970, los movimientos estudiantiles, como el de 1968, y por supuesto la experiencia de las comunidades insurgentes zapatistas desde 1994-, que han manifestado públicamente determinadas emociones de oposición como la desconfianza hacia el Estado, el dolor, el duelo y la "digna rabia".

El proceso de politización del trauma cultural lleva también a otro aspecto que es la necesidad de identificar a los ejecutores del evento traumático -o los perpetrators, en términos de Alexander (2016) - y el grupo social sobre quién hacer caer la responsabilidad moral de lo sucedido. En el caso mexicano, respecto a la desaparición forzada se responsabiliza directamente al gobierno (de hecho, el lema principal del movimiento es "Fue el Estado"), y al ejército mexicano como ejecutores, como lo muestra este extracto: "Ahora, 
como en el 68, el ejército desgraciadamente intervino, y no fue para proteger al pueblo, sino para asesinarlo" (I.44).

La necesidad de identificar al responsable conlleva a debilitar las emociones que cimientan la relación entre instituciones políticas y ciudadanía (cementing emotions), como la gratitud, la lealtad, la estima, la admiración, el miedo hacia la autoridad o la vergüenza de ir en contra de la autoridad, que son necesarias para mantener y fortalecer el "contrato social" entre un Estado y sus conciudadanos (Flam, 2005).

El proceso de disgregación de las emociones que cimientan se vincula a un proceso en el cual emergen lo que Flam (2005) define como emociones subversivas (subversive counter-emotions): el odio hacia el gobierno, el desprecio hacia los políticos, la rabia por la impunidad, y que producen un distanciamiento de la ciudadanía hacia el sistema político, como se muestra en el siguiente extracto: "Sin embargo, los del gobierno son los ladrones, los asesinos, y los que quieren siempre pisotear al pueblo. ¿Ya basta de tanta impunidad! ¡Ya basta de tanto salvajismo!” (I. 45).

Para terminar, el proceso de politización del trauma cultural lleva, entre otras cosas, a fortalecer el círculo del nosotros mostrado anteriormente. Si las emociones del trauma, como el duelo y el dolor, amplían y fortalecen la identidad colectiva, como se demuestra en otras investigaciones sobre los movimientos de las víctimas de guerra (Bayard de Volo, 2006; Schirmer, 1993), las emociones de la resistencia son fundamentales al determinar el antagonismo con otros actores, el "círculo del ellos", es decir, los responsables del evento traumático.

\section{Conclusiones: la construcción de una nueva narrativa social}

Para comprender por qué la desaparición forzada de los estudiantes de Ayotzinapa ha generado una respuesta inesperada en la sociedad mexicana, he propuesto analizar la respuesta a estos acontecimientos como un trauma cultural colectivo. El proceso de construcción del trauma cultural, como ya se ha explicado, se caracteriza no solamente por la tragedia misma del evento, sino por los significados que la sociedad ha atribuido a este evento y la interpretación de las emociones vinculadas.

En el caso del movimiento de solidaridad con Ayotzinapa, el trauma cultural colectivo ha sido construido a través de una serie de procesos de resignificación tanto de las víctimas como de quien ha experimentado el trauma. Por un lado, las emociones vinculadas a este han conformado el sentido compartido colectivamente de una comunidad (bajo amenaza); y por el 
otro, las emociones de la resistencia han determinado la identificación de los responsables y han hecho emerger las demandas sobre justicia y verdad de lo sucedido.

Coincido con la propuesta de Alexander (2004), en que la representación simbólica colectiva del trauma cultural vinculado al evento de la desaparición forzada genera otro marco interpretativo de la realidad; es decir, una nueva narrativa social caracterizada por cuatro dimensiones críticas situadas en un análisis secuencial, aunque no a nivel temporal.

En otras palabras, la nueva narrativa social que emerge desde el proceso analizado anteriormente se construye a través del análisis de cuatro dimensiones simbólicas de la desaparición forzada vinculadas entre ellas, aunque sucedan en tiempos cronológicos distintos. En cada dimensión, la colectividad traumatizada clarifica una serie de cuestiones que emergen a partir del evento traumático y que guían la construcción de esa nueva narrativa:

1. La naturaleza del dolor. En la primera dimensión, la comunidad traumatizada analiza qué ha sucedido, qué grupos sociales han sido afectados y cómo este trauma se vincula al resto de la sociedad. En este proceso, la comunidad determina, por ejemplo, si los estudiantes fueron atacados por estar relacionados con el crimen organizado o si fue una estrategia continuada de la "guerra sucia", promovida por el Estado mexicano para crear miedo. En esta dimensión se vincula el dolor del evento con la cotidianidad de los sujetos externos al trauma, haciendo emerger sentimientos de inseguridad, amenaza y miedo.

2. La naturaleza de la víctima. En esta dimensión de representación, la comunidad que se percibe traumatizada identifica qué grupos de personas han sido afectadas por ese dolor traumatizante. Se determina si es un solo grupo o se pueden relacionar otros grupos sociales. En el caso de Ayotzinapa, por ejemplo, se determina si son los estudiantes rurales las principales víctimas o toda la comunidad estudiantil en México, y si existen otras víctimas que sufrieron a manos del mismo responsable, y qué significados se les otorgan.

3. La relación entre el trauma de las víctimas y los otros. Una vez cristalizada la naturaleza del dolor y establecida la identificación de las víctimas, sigue una serie de cuestiones respecto a la relación simbólica entre las víctimas y los otros. En esta etapa, solamente si las víctimas son representadas en términos de valores compartidos por la amplia identidad colectiva mexicana, la sociedad será capaz de participar simbólicamente en la experiencia del evento que ha generado el trauma. 
Por ejemplo, los estudiantes son representados como seres que demandaban un futuro mejor para ellos y para el país. Los padres representan el derecho a la verdad y justicia, etcétera.

4. La atribución de responsabilidad. Esta es una etapa crítica en tanto la colectividad establece la identidad de los responsables y distribuye las consecuencias morales y materiales del evento traumático.

Para finalizar, interpretar el evento traumático de la desaparición forzada de los 43 estudiantes de Ayotzinapa como un trauma cultural, permite comprender por qué centenares de miles de mexicanos han roto la inacción social y han empezado a solicitar un cambio social. Como hemos podido ver, en México, los eventos de Ayotzinapa han creado una nueva narrativa social que guía, por un lado, la construcción simbólica y social de la realidad presente y de las expectativas futuras, caracterizadas por una búsqueda de seguridad a través de la solidaridad y el sentido de comunidad; y por otro, el rediseño de las relaciones con las instituciones, caracterizadas por un sentido de desconfianza e injusticia.

La nueva narrativa que emerge desde el evento traumático de Ayotzinapa resulta importante para la sociedad mexicana, pues ha permitido crear un puente entre eventos olvidados (la represión estudiantil de 1968), eventos violentos que han pasado desapercibidos (los miles de desaparecidos que hay actualmente en todo el país) y la necesidad de crear un futuro mejor.

\section{Referencias}

Alexander, Jeffrey (2002), "On the Social Construction of Moral Universals. The 'Holocaust' from War Crime to Trauma Drama”, en The European Journal of Social Theory, año 5, núm. 1, Reino Unido: Sage.

Alexander, Jeffrey (2004), “Toward a Theory of Cultural Trauma”, en Alexander, Jeffrey et al. [comps.], Cultural Trauma and Collective Identity, USA: University of California Press.

Alexander, Jeffrey (2016), "Culture trauma, morality and solidarity: The social construction of 'Holocaust' and other mass murders", en Thesis Eleven, vol. 132, núm.1. Disponible en: http://journals.sagepub.com/doi/abs/10.1177/0725513615625239 [01 de mayo de 2016].

Alonso-Sánchez, Jorge y Alonso-Reynoso, Carlos (2015), Una fuerte indignación que se convirtió en movimiento: Ayotzinapa, México: Universidad de Guadalajara.

Andretta, Massimiliano y Della Porta, Donatella (2008), "Surveying Protestors", en Della Porta, Donatella [ed.], Methodological Practices in Social Movement Research, Reino Unido: University Press.

Andretta, Massimiliano et al. (2002), Global, noglobal, new global. La protesta contro il G8 a Genova, Italia: Laterza.

Bayard de Volo, Lorenne (2006), “The Dynamics of Emotion and Activism: Grief, Gender, and Collective Identity in Revolutionary Nicaragua", en Mobilization: An International Quarterly, año 11, núm. 4, USA: San Diego University. 
Benski, Tova (2005), "Breaching events and the emotional reactions of the public: Women in Black in Israel", en Flam, Helena y King, D. [eds.], Emotions and Social Movement, Inglaterra: Routledge.

Benski, Tova (2011), "Emotion maps of participation in protest: the case of Women in Black against the occupation in Israel', en Research in Social Movements, Conflicts and Change, vol. 31, USA: Emerald Books.

Caruth, Cathy (1996), Unclaimed Experience: Trauma, Narrative, and Historyi, USA: Johns Hopkins University Press.

Champagne, Rosaria (1996), The Politics of Survivorship, USA: New York University Press.

CIDH (Comisión Interamericana de Derechos Humanos) (2015), Informe Anual de la Comisión Interamericana de Derechos Humanos, USA: Organización de Estados Americanos.

CNDH (Comisión Nacional de los Derechos Humanos) (2016), Informe especial sobre desplazamiento forzado en México, México: Comisión Nacional de los Derechos Humanos.

Collins, Randall (2001), "Social Movement and Focus of Emotional Attention”, en Goodwin, Jeff et al. [eds.], Passionate Politics: Emotions in Social Movements, USA: University of Chicago Press.

Collins, Randall (2012), "C-escalation and D-escalation: a Theory of the Time-dynamics of Conflict”, en American Sociological Review, vol.77, núm. 1, USA: American Sociological Association.

Flam, Helena (2005), “Emotion's map: a research agenda”, en Flam, Helena y King, Debra [eds.], Emotions and Social Movement, Inglaterra: Routledge.

Giesen, Bernhard (2004), "The Trauma of Perpetrators: The Holocaust as the Traumatic Reference of German National Identity”, en Alexander, Jeffrey et al. [comps.], Cultural Trauma and Collective Identity, USA: University of California Press.

Gould, Deborah (2009), Moving Politics: Emotion and ACT UP's Fight Against AIDS, USA: University of Chicago Press.

GTDFI (Grupo de Trabajo sobre las Desapariciones Forzadas) (2015), Informe del Grupo de Trabajo sobre las Desapariciones Forzadas o Involuntarias 2015, USA: ONU.

Hochschild, Ariel (1975), "The Sociology of Feeling and Emotion: Selected Possibilities", en Millman, M. y Moss, Kanter [eds.], Another Voice, USA: Anchor.

Hochschild, Ariel (1979), "Emotion work, feeling rules, and social structure", en American Journal of Sociology, vol. 85, USA: University Chicago Press.

Instituto Belisario Domínguez (2016), Desaparición forzada y tortura en México. La perspectiva de organismos internacionales y datos según averiguaciones previas. Temas estratégicos 32, México: Senado de la República.

Jasper, James (1998), “The Emotions of Protest: Affective and Reactive Emotions in and around Social Movements”, en Sociological Forum, vol. 13, USA: Eastern Sociological Society.

Jasper, James (2011), "Emotions and Social Movements: Twenty Years of Theory and Research”, en Annual Review of Sociology, vol. 37, Canadá: Annual Reviews.

Krotz, Esteban y Llanes, Rodrigo (2015), Ayotzinapa: pequeña bibliografía comentada a nueve meses de la masacre. Disponible en línea: http://www.comecso.com/?foro=estebankrotz-y-rodrigo-llanes-ayotzinapa-pequena-bibliografia-comentada-a-nueve-mesesde-la-masacre [01 de mayo de 2016].

LAOMS (2015a), "Números de eventos de protestas de movimientos sociales en México" [Data file: Num EPs Movimientos Sociales (MS).xlsx, hoja 1]. 
LAOMS (2015b), "Eventos de Protesta en México y Actores Sociales" [Data file: Num EPs Todo tipo de actor (MS y ACNO).xlsx, hoja 1].

Open Society Foundations (2016), Atrocidades innegables. Confrontando crimenes de lesa humanidad en México, USA: Open Society Foundations.

Poma, Alice y Gravante, Tommaso (2016), "Environmental self-organized activism: emotion, organization and collective identity in Mexico", en International Journal of Sociology and Social Policy, vol. 36, núm. 9/10. Disponible en: http://dx.doi.org/10.1108/ IJSSP-11-2015-0128 [01 de mayo de 2016].

Schedler, Andreas (2014), Encuesta Nacional de Violencia Organizada = Mexican National Survey on Organized Violence (ENVO) [en línea], México: Banco de Información para la Investigación Aplicada en Ciencias Sociales, Centro de Investigación y Docencia Económicas. Disponible en: http://hdl.handle.net/10089/17069 [01 de mayo de 2016]. Schirmer, Jennifer (1993), "The Seeking of Truth and the Gendering of Consciousness: The Comadres of El Salvador and the Conavigua Widows of Guatemala”, en Radcliffe, Sarah y Westwood, Sallie [eds.], Viva: Women and Popular Protest in Latin America, USA: Routledge.

Segob (Secretaría de Gobernación) (2016), Informe Nacional de Datos de Personas Extraviadas o Desaparecidas, México: Secretaría de Gobernación.

van Stekelenburg, Jacquelien et al. (2012), "Contextualizing Contestation: Framework, Design, and Data”, en Mobilization: An International Quarterly, año 17, núm. 3, USA: San Diego University.

Whittier, Nancy (2001), "Emotional Strategies: The Collective Reconstruction and Display of Oppositional Emotions in the Movement against Child Sexual Abuse”, en Goodwin, Jeff et al. [eds.], Passionate Politics: Emotions and Social Movements, USA: University of Chicago Press.

Tommaso Gravante. Doctor en Ciencias Políticas. Becario del Centro de Investigaciones Interdisciplinarias en Ciencias y Humanidades, UNAM, México. Líneas de investigación: emociones y protesta, movimientos de base, acción colectiva y cambio social. Publicaciones recientes: Gravante, Tommaso y Sierra, Francisco, Networks, Movements and Technopolitics in Latin America. Critical Analysis and Current Challenges, Suiza: Palgrave Macmillan, IAMCR Series. Disponible en: https://doi.org/10.1007/978-3-319-655604 (2018); Gravante, Tommaso y Poma, Alice, "Emotions in Inter-Action in Environmental Re-Sistances. The Case Of Comité Salvabosque In Mexico”, en PArtecipacione e COnflitto. The Open Journal of Sociopolitical Studies, vol. 10, núm. 3, DOI: 10.1285/i20356609v10i3p896 (2017); Gravante, Tommaso y Poma, Alice, "Protest, emotion and change: an analysis of two women's collectives fighting against machismo in Oaxaca, Mexico", en Interface: a journal for and about social movements, vol. 9, núm. 1 (2017).

Recepción: 12 de febrero de 2018.

Aprobación: 12 de marzo de 2018. 